\title{
Improvement of Salt Tolerance in Transgenic Potato Plants by Glyceraldehyde-3 Phosphate Dehydrogenase Gene Transfer
}

\author{
Mi-Jeong Jeong*, Soo-Chul Park, and Myung-Ok Byun \\ Division of Molecular Genetics, National Institute of Agricultural Science and Technology, Rural Development Administration, Suwon \\ 441-707, Korea.
}

(Received April 2, 2001; Accepted June 23, 2001)

In the previous experiment, we isolated and characterized glyceraldehyde-3-phosphate dehydrogenase (GPD) gene of the oyster mushroom, Pleurotus sajor-caju. Expression levels of the GPD gene in the mycelia of $P$. sajor-caju was significantly increased by exposing the mycelia to abiotic stresses, such as salt, cold, heat, and drought. We also showed that GPD confers abiotic stress resistance when introduced into yeast cells. The survival rate of the transgenic yeast cell that harbored the GPD gene was significantly higher when the yeast cells were subjected to salt, cold, heat, and drought stresses, compared with the yeast that was transformed with the pYES2 vector alone. In order to investigate the functional role of the P. sajor-caju GPD gene in higher plant cells, the complete $P$. sajor-caju GPD cDNA was fused into the CaMV35S promoter and then introduced into potato plants. Putative potato transformants were screened by using PCR. Twentyone transformants were further analyzed with RTPCR to confirm the expression of $P$. sajor-caju GPD. A RT-PCR Southern blot analysis revealed that 12 transgenics induced the $P$. sajor-caju GPD gene expression. A bioassay of these transformants revealed that the $P$. sajor-caju GPD gene was enough to confer salt stress resistance in the potato plant cell system. Results showed that $P$. sajor-caju GPD, which was continuously expressed in transgenic potato plants under normal growing conditions, resulted in improved tolerance against salt loading.

Keywords: $P$. sajor-caju GPD Gene; Salt Tolerance; Transgenic Potato.

\footnotetext{
* To whom correspondence should be addressed. Tel: 82-31-290-0340; Fax: 82-31-290-0392

E-mail:mjjeong@rda.go.kr
}

\section{Introduction}

Plants are exposed to a variety of biotic or abiotic stresses, such as drought, salt loading, and freezing that influence their development, growth, and productivity. One of the major abiotic stresses that affect plant productivity is water stress resulting from drought or salinity (Gueta-Dahan et al., 1997).

Osmotic stress is mainly a result of drought, chilling, freezing, or excessive salt in water (Zhu et al., 1997). Soil salinity is also a major environmental stress, which is a substantial constraint to crop production, both for dryland and irrigated agriculture. Osmotic stress induces a specific cellular response that includes a change in the activity of solute transporters (Csonka, 1989; Lucht and Bremer, 1994; Luyten et al., 1995), the expression of genes that encode enzymes required for osmolytes synthesis (Albertyn et al., 1999; Csonka, 1989; Levin and Errde, 1995), and stress resistance (Vaidyanathan et al., 1999; Xu et al., 1996). Many organisms have evolved traits that enable them to survive in extreme environments. Therefore, the genes that give these properties can potentially be introduced into higher plants. Recently, attention has been directed towards higher plants. There have been successful attempts to introduce stress-toleranceconferring genes (Holmberg and Bulow, 1998; Ingram and Bartels, 1996; Zhu et al., 1997). The most successful approach is the introduction of genes that encode enzymes in the biosynthetic pathways of the osmoprotectant and osmolytes. The importance of osmolyte accumulation was emphasized by the finding that trans-

Abbreviations: BA, benzyl aminopurine; GA, gibberellic acid; GPD, glyceraldehyde-3-phosphate dehydrogenase; GUS, $\beta$-glucuronidase; LEA, late embryogenesis abundant; MS, murashige and skoog medium; NAA, naphthalene acetic acid; PEP, Phosphoenol pyruvate; RT-PCR, reverse transcriptasepolymerase chain reaction. 
genic tobacco that overexpresses a bacterial mannitol 1phosphate dehydrogenase gene accumulated mannitol and acquired increased tolerance to high salt stress (Tarczynski et al., 1992; 1993; Zhu et al., 1997). Transgenic tobacco plants that overexpress proline, a common compatible osmolytes inducible by stress, performed better under conditions of drought (Holmberg et al., 1997; $\mathrm{Hu}$ et al., 1992; Kishor et al., 1995). Environmental stresses, such as heat shock and anaerobiosis, are known to increase the mRNA level of the GPD gene, which encodes glyceraldehyde-3-phosphate dehydrogenase in all kinds of organisms, including plants, fungi, and mammals. In addition to heat shock and anaerobiosis, salt stress is also known to induce the GPD gene expression at the transcriptional level in A. nidulans (Redkar et al., 1996; 1998).

In a previous experiment, the GPD gene of the oyster mushroom, Pleurotus sajor-caju, was isolated and the expression pattern under various abiotic stresses was characterized. The $P$. sajor-caju GPD gene significantly increased its mRNA level under salt, dry, chilling, and heat condition. Transgenic yeast cells that overexpress the $P$. sajor-caju GPD gene increased their tolerance to these abiotic stresses (Jeong et al., 2000). In this study, we confirmed that the overexpressed heterologous GPD gene can create salt stress resistance in transgenic potato plants.

\section{Materials and Methods}

Plasmid construction The pBI121 was used in the transformation of the chimeric gene, CaMV35S promoter-P. sajor-caju GPD cDNA, into potato plants. The GUS coding region in pBI121 was replaced by the $1.2 \mathrm{~kb}$ full length cDNA of the $P$. sajor-caju GPD gene, in which the GPD gene was placed under the transcriptional control of the CaMV35S promoter. This construct was introduced into Agrobacterium tumefaciens, LBA4404, according to the freeze-thaw method (Gelvin et al., 1988).

Plant materials and growth condition Experiments were carried out with the potato plant (Solanum tuberosum L., cultivar Daejima), which was obtained from the National Institute of Horticultural Research, Rural Development Administration (NIHR, Korea). Stock plants were maintained on PM media (MS salt, 3\% sucrose, and $0.8 \%$ phytoagar). These plants were cultured in test tubes and grown at $19^{\circ} \mathrm{C}$ and exposed for $24 \mathrm{~h}$ to 2,000-3,000 Lux illumination from white fluorescent day light lamps. Four-week-old potato plants were used for transformation.

Transformation and regeneration of transgenic potato plants Stems of potato plants were chopped and all of the inter-nodes were cut at about $3-5 \mathrm{~mm}$-long. Several pieces of the potato internodes were placed in a dish and the Agrobacterium cells were added. The dish was swirled and then let stand for $15 \mathrm{~min}$. The internodes were then placed onto 1/10 MSO plates that had been covered with sterile Whatman No. 1 filters. After the cocultivation for $48 \mathrm{~h}$ in the dark, the internodes were transferred to the PC medium (MS salt supplemented with $3 \%$ sucrose, 0.1 mg NAA, $0.5 \mathrm{mg} \mathrm{BA}$, at $\mathrm{pH} 5.6$, solidified with $0.8 \%$ phytoagar) for an initial callus induction. Kanamycin $50 \mathrm{mg} / \mathrm{L}$ and Carbenicillin $500 \mathrm{mg} / \mathrm{L}$ were added for transformant selection and to kill the bacteria, respectively. Four weeks later, the explants were transferred to the PS medium (MS medium supplemented with 3\% sucrose, $500 \mathrm{mg}$ BA, $5 \mathrm{mg} \mathrm{GA3}$, at pH 5.7 solidified with $0.8 \%$ phytoagar containing Kanamycin $50 \mathrm{mg} / \mathrm{L}$ ). Induced shoots were transferred to a PM solidified medium without growth regulators, supplemented with $3 \%$ sucrose, containing 50 mg Kanamycin and 100 mg Cefotaxime.

Purification of DNA and RNA Genomic DNA and total RNA were isolated from the leaves of potato leaves using a rapid extraction procedure described by Graham (1994) and by a $\mathrm{LiCl}$ precipitation protocol adapted from the procedure of Sambrook and Russell (2001), respectively.

Polymerase chain reaction (PCR) analysis To determine the presence of the transferred $P$. sajor-caju GPD gene in transgenic potato plants, PCR was performed with total genomic DNA that was extracted from the untransgenic plants, and each transgenic potato plant was used as a template. Two primers, 5'-CAA GGC TTG CTT CAT AAA CC-3' (CaMV35S promoter specific sense primer) and 5'-GAT CGG CTT CCC CTC AAC GAT-3' ( $P$. sajor-caju GPD gene specific antisense primer) that corresponded to the nucleotide sequences of the CaMV35S promoter and P. sajor-caju GPD cDNA, respectively, were synthesized and used in PCR. The PCR amplification was performed by using a MJ research PCR system (PTC 200, MJ Research, USA). The samples were carried out through 35 cycles by using the following temperature sequence: $94^{\circ} \mathrm{C}$ for $1 \mathrm{~min}, 55^{\circ} \mathrm{C}$ for 1 $\min$, and $72^{\circ} \mathrm{C}$ for 2 min cycles preceded by denaturation for 5 $\min$ at $94^{\circ} \mathrm{C}$ and a final extension cycle at $72^{\circ} \mathrm{C}$ for $10 \mathrm{~min}$. The PCR products were electrophoresed through a $0.7 \%$ agarose gel.

RT-PCR and Southern blot analysis In order to check the GPD mRNA expression in transgenic potato plants, two primers, 5'-TAC GAC TCG GTC CAC GGC CG-3' (GPD specific sense primer) that corresponded to the nucleotide sequences of the $P$. sajor-caju GPD cDNA and 5'-TTTTTTTTTTTTTTT-3' (oligo$\mathrm{dT}$ antisense primer) were synthesized. The first-strand cDNA synthesis was performed in a $80 \mu \mathrm{l}$ reaction mixture that contained $5 \times$ buffer (Promega, USA), $0.25 \mathrm{mM}$ each of the four deoxynucleotides (dNTPs), $2 \mu \mathrm{g}$ of synthetic oligo-dT primer, 200 units of moloney murine leukemia virus (M-MLV) reverse transcriptase (Promega, USA), and $8 \mu \mathrm{l}$ DNAse-treated RNA, which had been preheated to $72^{\circ} \mathrm{C}$ for $2 \mathrm{~min}$. The reactions were performed at $37^{\circ} \mathrm{C}$ for $1 \mathrm{~h}$. The $15 \mu \mathrm{l}$ sample of first strand cDNA products was then employed as a template DNA in PCR for the amplification of the $P$. sajorcaju GPD cDNA. PCR am- 
plification was performed with a $100 \mu$ reaction mixture, which contained $10 \mu \mathrm{l} 10 \times$ buffer, $0.25 \mathrm{mM}$ dNTPs, $0.5 \mu \mathrm{g} P$. sajorcaju GPD specific sense primer, and $2.5 \mathrm{U}$ Taq Polymerase (Promega, USA), using a Peltier thermal cycler for 25 cycles. Each cycle consisted of $30 \mathrm{~s}$ at $94^{\circ} \mathrm{C}, 30 \mathrm{~s}$ at $48^{\circ} \mathrm{C}$, and $1 \mathrm{~min}$ at $72^{\circ} \mathrm{C}$. The RT-PCR product was separated on a $0.8 \%$ agarose gel and transferred onto a Hybond $\mathrm{N}^{+}$nylon membrane (Amersham, USA) by the capillary transfer method (Sambrook and Russell, 2001). A $0.5 \mathrm{~kb}$ internal fragment of the GPD cDNA was used as a probe. Hybridization was carried out for $16 \mathrm{~h}$ at $42^{\circ} \mathrm{C}$. The filters were washed twice with $2 \times$ SSC buffer that contained 6 $\mathrm{M}$ urea at $42^{\circ} \mathrm{C}$. They were washed again twice with $2 \times$ SSC buffer for $5 \mathrm{~min}$ at room temperature. For detection of the $P$. sajor-caju GPD signal, the ECL detection system was used (Amersham, USA).

Bioassay for salt tolerance To test whether overexpression of the $P$. sajor-caju GPD gene enhanced tolerance to salt stress, the wild-type and transgenic potato plant were grown in Jiffy-7 pots (Jiffy Product, Canada) under continuous illumination of 2,500 Lux at $19^{\circ} \mathrm{C}$ for four weeks. High-salt stress was conducted by soaking the pots that were planted with potato plants in $2 \mathrm{M}$ $\mathrm{NaCl}$ solution for $12 \mathrm{~h}$, and then transferred to the normal growing condition and grown for $10 \mathrm{~d}$.

\section{Results}

Determination of the real transformants by PCR Putative potato transformants were screened by using PCR. Total DNA was extracted from the wild-type and transgenic potato plants. Two primers, sense and antisense, were used in PCR. The sense primer landed on the CaMV35S promoter and the antisense primer landed on the GPD structural gene. Of the 43 putative transgenic potato plants, 41 have a $0.8 \mathrm{~kb}$ size band in the potato genome (Fig. 1). The result from PCR showed that 95\% of the plantlets were transformants.

Expression of the GPD gene To investigate whether the $G P D$ gene is expressed in the transgenic potato plants, transcription of the $P$. sajor-caju GPD gene was examined by RT-PCR Southern and Northern blot analysis. Total RNA, isolated from 21 transgenic plants and nontransgenic potato plants, were subjected to RT-PCR using the two primers described in Materials and Methods. A RT-PCR Southern blot analysis was performed using the GPD cDNA fragment as a probe. A RT-PCR Southern blot analysis showed the positive, a $1.5 \mathrm{~kb}$ size band in 12 transgenic lines, but no signal was detected in the nontransgenic control plants (data not shown). A Northern blot analysis was performed from the six transgenic potatoes that showed a constitutive expression of the GPD gene at different levels. Figure 2 shows that the expression profiles of GPD mRNA in the transgenic plant are

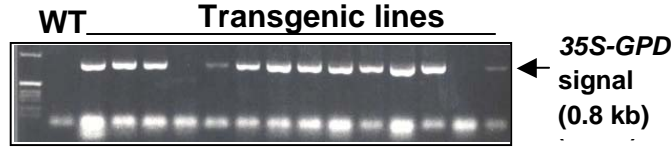

Fig. 1. Determination of the real transformant by PCR analysis. Two primers, the $35 S$ promoter specific sense primer and $P$. sajor-caju GPD gene specific antisense primer, were used in PCR with full genomic DNA that was isolated from each transgenic potato plant as a template. WT, wild type control plant; transgenic lines, independent transgenic plant.

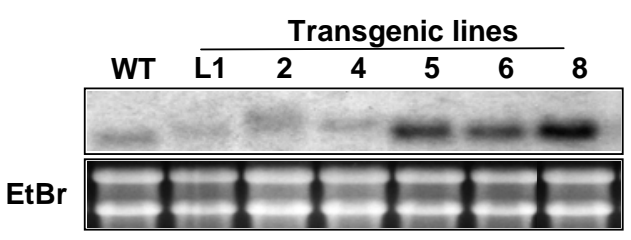

Fig. 2. Northern blot analysis to confirm the induction of $P$. sajor-caju GPD mRNA. The six selected transgenic potato plants. Each lane contained $15 \mu \mathrm{g}$ of total RNA that was prepared from the four-week-old potato plants. The probe used was a $0.7 \mathrm{~kb}$ EcoR1/Xho1 fragment that contained the 5' of P. sajorcaju GPD cDNA. WT, wild type control plant; L, independent transgenic plant.

not identical. In the Northern blot analysis, six independent transgenic potato plants exhibited variant degrees of the expression level; however, the expression pattern of the P. sajor-caju GPD gene was similar to that in the RTPCR Southern blot analysis. The GPD mRNA expression level of numbers 5, 6, and 8 lines was high, and the other transgenic lines were moderate or low. Also, a faint signal band was observed in the nontransgenic wild-type potato plant. The band size, however, is smaller than that of the transgenic plants; presumably this band of wild-type plant is the endogenous GPD gene of potato plants.

The GPD gene confers salt stress tolerance on transgenic potato plants To test whether overexpression of the $P$. sajor-caju GPD gene enhanced tolerance to salt stress, 4-week-old potato plants (wild-type and transgenic plants) were soaked in $2 \mathrm{M} \mathrm{NaCl}$ solution for $12 \mathrm{~h}$, and then transferred back to normal conditions for $10 \mathrm{~d}$. Six independent transgenic potato plants (lines 1, 2, 4, 5, 6, and 8) that were used in the Northern blot analysis were tested for bioassay of the salt tolerance. The wild-type plants died after $10 \mathrm{~d}$, whereas the transgenic plants were highly tolerant against the salt stress (Fig. 3). 


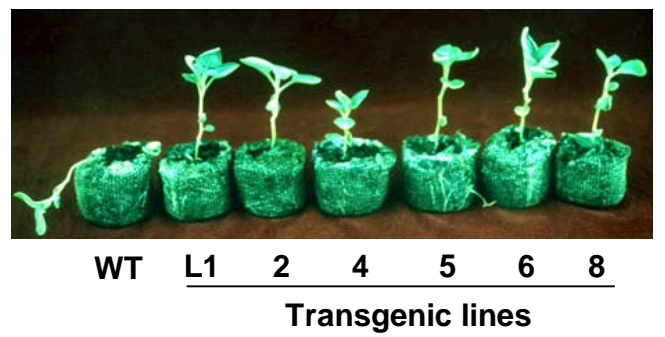

Fig. 3. Bioassay of transgenic potato plants, which have a constitutive $G P D$ gene expression under normal conditions. Six independent transgenic potato plants, which have different $G P D$ gene expression levels were grown in $2 \mathrm{M} \mathrm{NaCl}$ solution for 12 $\mathrm{h}$ and transferred back to the normal conditions to keep them growing for $10 \mathrm{~d}$. WT, wild type control plant; L, independent transgenic plant.

\section{Discussion}

Plant productivity is related to the ability of plants to respond and adapt to environmental stress. To develop crops that are tolerant to abiotic stress by using the traditional plant breeding technique is time-consuming and laborious. Therefore, genetic engineering has been used as a relatively fast and precise means of achieving improved stress tolerance. Recently, several different gene transfer approaches have been employed to improve the stress tolerance of plants (Holmberg and Bulow, 1998; Ingram and Bartels, 1996; Van Camp et al., 1996; Yeo et al., 2000; Zhu et al., 1997). Transgenic rice plants that express HVA1, a group3 LEA protein from barley, showed an enhanced tolerance to drought and salt stress (Xu et al., 1996). When the betA gene, which encoded choline dehydrogenase, was introduced into tobacco, salt-tolerant phenotypes were achieved (Lilius et al., 1996). Another approach was conducted by Hayashi et al. (1997). To create the salt and freezing-tolerant in transgenic plants, the codA gene from Arthrobacter globiformis, which encoded choline oxidase, was introduced into the Arabidopsis. This resulted in improved salt and freezing tolerance in the transgenic plant.

In the previous experiment, a cDNA encoding glyceraldehyde-3-phosphate dehydrogenase (GPD) was isolated from Pleurotus sajor-caju. Its expression level was significantly increased by exposing the mycelia to various abiotic stresses. When the GPD gene was overexpressed in the yeast cell, the survival rate was significantly high, compared with the control yeast cells transformed with the pYES2 vector (Jeong et al., 2000). The result with the $G P D$ transgenic yeast experiment suggests that it may be possible to use this gene for making transgenic crop plants, which are highly tolerant to abiotic stress. GPD (EC1.2.1.12) catalyze the $\mathrm{NAD}^{+}$-dependent oxidative phosphorylation of the glyceraldehyde -3- phosphate to 1,3-bisphosphate glyceric acid, which is one of the most important metabolic reactions in the glycolytic pathway (Hirano et al., 1999; Niu et al., 1994; Redkar et al., 1998). The GPD gene from all kinds of organisms (including plants, microbes, and animals) is known to be responsive to heat and anaerobic stress (Ito et al., 1996; Niu et al., 1994; Redkar et al., 1996). The activation of the GPD gene under heat and anaerobic stress may be an adaptive response to heat-stress-related mitochondrial damage, or anaerobic stress-induced inhibition of oxidative phosphorylation. The facultative halophyte Mesembryanthemun crystallinum is transcriptionally up-regulated by several genes. This includes $P p c 1$, which encodes the major carboxylating enzyme PEP carboxylase, and Gap1 in response to environmental stresses, such as high salinity and drought (Schaeffer et al., 1994; Vernon et al., 1993).

In the present study, we were able to produce transgenic potato plants that were highly salt-tolerant by the overexpression of the $P$. sajor-caju GPD gene. To investigate the salt tolerance of GPD transgenic potato plants, six independent transgenic lines were selected according to the RT-PCR result. When the plants that were grown in pots were exposed to salt stress, the wild-type plants died after $10 \mathrm{~d}$, but the transgenic plants survived (Fig. 3). Although these six transgenics showed different expression levels of $P$. sajor-caju GPD mRNA, the result of the bioassay revealed that all transgenics increased their salt stress tolerance. This suggests that the GPD expression level may not be related to salt tolerance. However, it is clear that the constitutive expression of the GPD cDNA of $P$. sajor-caju should be quite useful for improving salt stress tolerance in the plant system, at least in the potato plant.

These results suggest that the $P$. sajor-caju GPD gene can be used to improve the salt tolerance of agriculturally important crops through gene transfer. Another possibility is that the $P$. sajor-caju GPD also functions in other stress responses in addition to salt. Future research should determine whether or not the GPD gene transferred transgenic potato plants have other stress tolerances, such as cold, drought, and heat stress.

\section{References}

Albertyn, J., Hohmann, S., Thevelein, J. M., and Prior, B. A (1994) GPD1, which encodes glycerol-3-phosphate dehydrogenase, is essential under osmotic stress in Saccharomyces cerevisiae, and its expression is regulated by the highosmolarity glycerol response pathway. Mol. Cell. Biol. 14, 4135-4144.

Csonka, L. N. (1989) Physiological and genetic responses of bacteria to osmotic stress. Microbiol. Rev. 53, 121-147.

Gelvin, S. B. and Schilperoort, R. A. (1988) Plant molecular biology. Kluwer Academic Publishers. 
Graham, G. C. (1994) A simplified method for the preparation of fungal genomic DNA for PCR and RAPD analysis. Biotechniques 16, 49-50.

Gueta-Dahan, Y., Yaniv, Z., Zilinskas, A., and Ben-Hayyim, G. (1997) Salt and oxidative stress: similar and specific responses and their relation to salt tolerance in Citrus. Planta 203, 460-469.

Hayashi, H., Alia, Mustardy, L, Deshnium, P., Ida, M., and Murata, N. (1997) Transformation of Arabidopsis thaliana with the $\operatorname{cod} A$ gene for choline oxidase; accumulation of glycinebetaine and enhanced tolerance to salt and cold stress. Plant J. 12, 133-142.

Hirano, T., Sato, T., Okawa, K., Kanda, K., Yaegashi, K., and Enei, H. (1999) Isolation and characterization of the glyceraldehyde-3-phosphate dehydrogenase gene of Lentinus edodes. Biosci. Biotechnol. Biochem. 63, 1223-1227.

Holmberg, N. and Bulow, L. (1998) Improving stress tolerance in plants by gene transfer. Trends in Plant Sci. 3, 61-66.

Holmberg, N., Lilius, G., Bailey, J. E., and Buelow, L. (1997) Transgenic tobacco expressing Vitrecoscilla hemoglobin exhibits enhanced growth altered metabolite production. Nat. Biotechnol. 15, 244-247.

Hu, C., Delauney, A., and Verma, D. P. S. (1992) A bifunctional enzyme (1-pyrroline-5- carboxylate synthetase) catalyzes the first two steps in proline biosynthesis in plants. Proc. Natl. Acad. Sci. 89, 9354-9358.

Ingram, J. and Bartels, D. (1996) The molecular basis of dehydration tolerance in plants. Annu. Rev. Plant Physiol. Plant Mol. Biol. 47, 377-403.

Ito, Y., Pagano, P. J., Tornheim, K., Brecher, P., and Cohen, R. A. (1996) Oxidative stress increases glyceraldehyde-3-phosphate dehydrogenase mRNA levels in isolated rabbit aorta. Am. Physiol. Soc. 270, H81-H87.

Jeong, M.-J., Park, S.-C., Kwon, H.-B., and Byun, M.-O. (2000) Isolation and characterization of the gene encoding glyceraldehyde-3-phosphate dehydrogenase. Biochem. Biophy. Res. Comm. 278, 192-196.

Levin, D. F. and Errede, B. (1995) The proliferation of MAP kinase signaling pathways in yeast. Curr. Opin. Cell Biol. 7, 197-202.

Lilius, G., Holmberg, N., and Bulow, L. (1996) Enhanced NaCl stress tolerance in transgenic tobacco expressing bacterial choline dehydrogenase. Biotechnology 14, 177-180.

Lucht, J. M. and Bremer, E. (1994) Adaptation of Escherichia coli to high osmolarity environments: osmoregulation of the high-affinity glycine betaine transport system proU. FEMS Microbiol. Rev. 14, 3-20.

Luyten, K., Albertyn, J., Skibbe, F. W., Prior, B. A., Ramos, J., Thevelein, J. M., and Hohmann, S. (1995) Fps1, a yeast member of the MIP family of channel proteins, is facilitator for glycerol uptake and efflux and is inactive under osmotic stress. EMBO J. 14, 1360-1371.

Niu, X., Wang, H., Bressan, R. A., and Hasegawa, P. M. (1994) Molecular cloning and expression of a glyceraldehyde-3phosphate dehydrogenase gene in a desert halophyte, Atriplex nummularia L.. Plant Physiol. 104, 1105-1106.

Redkar, P. J., Lemke, P. A., and Singh, N. K. (1996) Isolation of differentially expressed cDNA clones from salt-adapted Aspergillus nidulans. Curr. Genet. 29, 130-135.

Redkar, R. J., Herzog, R. W., and Singh, N. K. (1998) Transcriptional activation of the Aspergillus nidulans gpdA promoter by osmotic signals. Appl. Environ. Microbiol. 64, 22292231.

Sambrook, J. and Russell, D. W. (2001) Molecular cloning: a laboratory manual, 3rd ed. Cold Spring Harbor Laboratory Press, Cold Spring Harbor, N.Y.

Schaeffer, H., Forsthoefel, N. R., and Cushman, C. (1995) Identification of enhancer and silencer regions involved in saltresponsive expression of Crassulascean acid metabolism (CAM) genes in the facultative halophyte Mesembryanthemum crystallinum. Plant Mol. Biol. 28, 205-218.

Tarczynski, M. C., Jensen, R. G., and Bohnert, H. J. (1992) Expression of a bacterial gene in transgenic tobacco leads to production and accumulation of mannitol. Proc. Natl. Acad. Sci. USA 89, 2600-2604.

Tarczynski, M. C., Jensen, R. G., and Bohnert, H. J. (1993) Stress protection of transgenic tobacco by production of the osmolyte mannitol. Science 259, 508-510.

Vaidyanathan, R., Kuruvilla, S., and George, T. (1999) Characterization and expression pattern of an abscisic acid and osmotic stress responsive gene from rice. Plant Sci. 140, 25-36.

Van Camp, W., Capiau, K., Van Montagu, M., Inze, D., and Slooten, L. (1996) Enhancement of oxidative stress tolerance in transgenic tobacco plants overproducing Fe-superoxide dismutase in choloroplasts. Plant Physiol. 112, 525-535.

Vernon, D. M., Ostrem, J. A., and Bohnert, H. J. (1993) Stress perception and response in a facultative halophyte; the regulation of salinity-induced genes in Mesembryanthemum crystallinum. Plant Cell Environ. 16, 437-444.

Xu, D. P., Duan, X., Wang, B., Ho, T. D., and Wu, R. (1996) Expression of a late embryogenesis abundant protein gene, HVA1, from barley confers tolerance to water deficits and salt stress in rice. Plant Physiol. 110, 249-257.

Yeo, E.-T., Kwon, H.-B., Han, S.-E., Lee, J.-T., Ryu, J.-C., and Byun, M.-O. (2000) Genetic engineering of drought resistant potato plants by introduction of the trehalose-6-posphate synthase(TPS1) gene from Saccharomyces cerevisiae. Mol. Cells 10, 263-268.

Zhu, J.-K., Hasegawa, P. M., and Brssan, R. A (1997) Molecular aspects of osmotic stress in plants. Crit. Rev. Plant Sci. 16, 253-277. 